\title{
PENILAIAN KONSUMEN TERHADAP KOMPONEN 7P PRODUK “CHATIME” MANADO TOWN SQUARE
}

\author{
Melisa Verlina Seran \\ Leonardus Ricky Rengkung \\ Tommy Fredy Lolowang
}

\begin{tabular}{lrr}
\hline Naskah diterima melalui Website Jurnal Ilmiah agrisosioekonomi@ unsrat.ac.id & $:$ & Rabu, 14 Oktober 2020 \\
Disetujui diterbitkan & $:$ & Selasa, 27 Oktober 2020 \\
\hline
\end{tabular}

\begin{abstract}
This study aims to determine the consumer assessment of the 7P component of the Chatime Manado Town Square product. This research was conducted from January to March 2020. The data used in this study are primary data and secondary data. Primary data were obtained through direct interviews with 30 respondents using a questionnaire. Secondary data were obtained from books and journals related to this research topic. The results showed that the $7 P$ component elements of the consumer products assessed, it's just that the products were always available, consumers considered disagreeing because according to consumers, Chatime Manado Town Square still often ran out of stock of certain drinks. At price and place, consumers agree. Promotion and consumer people judge neutral. In the process section, consumers agree that they agree, it's just that in the process section to get a fast product, consumers think they don't agree because according to consumers, the process to get the product has to wait in a queue and still takes quite a long time to get the product. Then on physical evidence, consumers assess agree, but in the complete room facilities section, consumers consider that they strongly disagree because according to consumers there is no wifi and consumers feel that tables and seats are still lacking.
\end{abstract}

Keywords : Marketing Mix, Product, Price, Place, Promotion, People, Process, Physical evidence.

\begin{abstract}
ABSTRAK
Penelitian ini bertujuan untuk mengetahui penilaian konsumen terhadap komponen 7P produk Chatime Manado Town Square. Penelitian ini dilaksanakan pada bulan Januari sampai Maret 2020. Data yang digunakan dalam penelitian ini adalah data primer dan data sekunder. Data primer diperoleh melalui wawancara langsung kepada 30 responden dengan menggunakan kuesioner. Data sekunder diperoleh dari buku-buku, dan jurnal yang berkaitan dengan topik penelitian ini. Hasil penelitian menunjukkan bahwa unsur komponen 7P terhadap product konsumen menilai setuju, hanya saja pada produk selalu tersedia konsumen menilai tidak setuju karena menurut konsumen, Chatime Manado Town Square masih sering kehabisan stok minuman tertentu. Pada price dan place konsumen menilai setuju. Promotion dan people konsumen menilai netral. Pada bagian process konsumen menilai setuju, hanya saja pada bagian proses untuk mendapatkan produk cepat konsumen menilai tidak setuju karena menurut konsumen, proses untuk mendapatkan produk harus menunggu antrian dan masih memerlukan waktu yang cukup lama untuk mendapatkan produk. Kemudian pada physical evidence konsumen menilai setuju tetapi pada bagian fasilitas ruangan lengkap konsumen menilai sangat tidak setuju karena menurut konsumen tidak terdapat wifi serta konsumen merasa meja dan tempat duduk yang masih kurang.
\end{abstract}

Kata Kunci : Bauran Pemasaran, Product, Price, Place, Promotion, People, Process, Physical evidence. 


\section{PENDAHULUAN}

\section{Latar Belakang}

Perindustrian merupakan salah satu komponen perekonomian yang berkembang pesat dalam peningkatan kondisi perekonomian nasional. Salah satunya adalah industri food and beverages. Pada tahun 2018 industri makanan dan minuman tumbuh hinggah 8,67\% atau melampaui pertumbuhan ekonomi nasional sebesar 5,27\% (Kementerian perindustrian 2018).

Industri makanan dan minuman di Indonesia banyak dimasuki oleh produk asing dengan strategi waralaba. Indonesia menjadi salah satu sektor yang paling banyak diminati dan dimasuki oleh investor-investor asing. Pada tahun 2013, jumlah waralaba asing di Indonesia mencapai 400 waralaba (Antarnews.com, 2013).

Dengan adanya industri food and beverages, menghadirkan berbagai macam produk minuman yang sejenis, salah satunya adalah minuman yang berasal dari Taiwan yaitu Chatime yang menyediakan minuman berbahan dasar teh. Chatime merupakan minuman kekinian asal Taiwan yang didirikan pada tahun 2005. Sebuah konsep teh unik yang didedikasikan untuk membuat teh alternatif yang lebih sehat, dan menyegarkan untuk dikonsumsi (Indriyani, 2014). Kaitannya dengan industri food and beverages, maka dalam hal untuk memasarkan suatu produk, perlu ada evaluasi yang tepat, (Payne, 2001). Dalam penelitian ini menggunakan konsep 7P dengan mengevaluasi product, price, place, promotion, people, proses, physical evidence. Evaluasi adalah proses penentuan nilai untuk suatu hal atau objek yang berdasarkan pada acuan-acuan tertentu untuk menentukan tujuan.

Product merupakan barang fisik, jasa ataupun kombinasi keduanya, yang ditawarkan kepada pasar sasaran. Chatime Manado Town Square selalu berusaha mempertahankan kualitas produk teh yang khas dari Taiwan, dengan sebagian bahan baku berasal dari Taiwan. Price merupakan sejumlah uang yang harus dikeluarkan pelanggan untuk memperoleh produk hasil perusahaan. Place merupakan perencanaan dan pelaksanaan program penyaluran produk melalui lokasi pelayanan yang tepat, sehingga produk berada pada tempat yang tepat. Chatime berada di Manado Town Square 3 lantai 1 unit 47 jalan Pierre Tendean, Sario Manado. Promotion merupakan kombinasi dari variabel-variabel periklanan, penjualan tatap muka, promosi penjualan, dan publisitas yang dilakukan perusahaan dalam upaya mengkomunikasikan produk kepada para pelanggan (konsumen) termotivasi/terdorong untuk melakukan pembelian. Chatime Manado Town Square memanfaatkan perkembangan teknologi dan internet seperti, facebook, instagram, dan twitter sebagai sarana publikasi dan promosi. People merupakan orang-orang yang terlibat langsung dalam menjalankan segala aktivitas perusahaan, dan merupakan faktor yang memegang peranan penting bagi semua organisasi. Process mempunyai arti suatu upaya perusahaan dalam menjalankan dan melaksanakan aktivitasnya untuk memenuhi kebutuhan dan keinginan konsumennya. Physical evidence merupakan bukti fisik, karakteristik yang menjadi persyaratan yang bernilai tambah bagi konsumen dalam perusahaan jasa yang memiliki karakter.

Dari penilaian konsumen dapat ditemukan masalah yang ada pada Chatime Manado Town Square yaitu masalah pada komponen $7 \mathrm{P}$ product yaitu produk selalu tersedia yang masih sering kehabisan stok minuman tertentu, kemudian process yaitu proses untuk mendapatkan produk cepat masih memerlukan waktu yang cukup lama untuk mendapatkan produk, serta physical evidence yaitu fasilitas ruangan lengkap Chatime tidak memiliki wifi, dan tempat duduk dan meja yang masih kurang.

Berdasarkan uraian diatas, maka penulis tertarik untuk melakukan penelitian pada Chatime untuk melihat penilaian konsumen terhadap komponen 7P yang ada di Chatime Manado Town Square.

\section{Agribisnis Minuman Ringan}

Asosiasi industry minuman ringan (Asrim) menyatakan realisasi produksi pada tahun 2019 menunjukkan sinyal positif. Asosiasi memprediksi produksi hingga akhir tahun akan lebih tinggi dari realisasi pertumbuhan tahun lalu. Ketua Asrim, Triyono Pridjosoesilo mengatakan produksi minuman ringan pada tahun 2019 tumbuh $2 \%$. Namun, Triyono menilai pertumbuhan tersebut merupakan sinyal positif bagi industri minuman nasional. Contoh agribisnis minuman ringan yang semakin dikenal namanya yaitu Starbucks, Thai tea, Sharetea, dan Chatime. 


\section{Minuman Chatime}

Chatime adalah sebuah jaringan kedai minuman teh susu mutiara (bubble tea) asal Taiwan. Salah satu minuman teh yang dapat dikonsumsi langsung yang dibuat atau diracik menjadi minuman bubble tea. Minuman yang dibuat dari bahan-bahan yang dipercaya kualitasnya (Sri Rezeki, 2016).

\section{Pengertian Pemasaran}

Pemasaran merupakan kegiatan yang penting dalam perusahaan dimana keberhasilan pemasaran dalam perusahaan akan sangat menentukan tingkat kemajuan perusahaan. Bila suatu perusahaan memiliki strategi pemasaran yang tepat maka output yang dikeluarkan perusahaan akan berjalan lancar dan mendapat keuntungan, dimana keuntungan tersebut yang menjadi tujuan utama yang dicari oleh setiap perusahaan. Pemasaran adalah suatu kegiatan berupa merencanakan, menentukan harga dan mempromosikan barang dan jasa untuk memenuhi kebutuhan konsumen yang ada (Kotler, 2008).

\section{Rumusan Masalah}

Berdasarkan latar belakang maka yang menjadi masalah dalam penelitian ini adalah komponen 7P seperti apakah yang diterapkan di Chatime Manado Town Square?

\section{Tujuan Penelitian}

Tujuan dari penelitian ini untuk mengetahui penilaian konsumen terhadap komponen 7P produk Chatime Manado Town Square. bagi:

1. Bagi Peneliti

Untuk menambah wawasan pengetahuan dan meningkatkan pemahaman mengenai bauran pemasaran di Chatime Manado Town Square.

2. Bagi Perusahaan

Penelitian ini dapat digunakan sebagai masukan untuk mengembangkan perusahaan Chatime terutama di Manado Town Square.

\section{METODE PENELITIAN}

\section{Tempat dan Waktu Penelitian}

Penelitian ini dilakukan selama tiga bulan yaitu dari bulan Januari 2020 sampai dengan bulan Maret 2020. Penelitian ini bertempat di Chatime Manado Town Square 3, lantai 1 unit 47, jln. Pierre Tendean, Sario, Manado.

\section{Metode Pengambilan Data}

Data yang digunakan dalam penelitian ini adalah data primer dan data sekunder. Data primer diperoleh melalui wawancara langsung dengan responden menggunakan kuesioner sebagai alat bantu pengumpulan data, yang berisi pertanyaan-pertanyaan yang berkaitan dengan unsur-unsur 7P product (produk), price (harga), place (tempat), promotion (promosi), people (sumber daya manusia), process (proses), physical evidence (lingkungan fisik tempat). Data sekunder diperoleh dari bukubuku dan jurnal yang berkaitan dengan topik penelitian ini. Metode pengumpulan data menggunakan metode survei. Wawancara dilakukan kepada konsumen yang memesan menu minuman. Penyebaran kuesioner dilakukan mulai tanggal 5-8 Februari 2020. Waktu penyebaran kuesioner dilaksanakan pada sore hari sampai malam hari.

\section{Metode Pengambilan Sampel}

Metode pengambilan sampel dilakukan dengan menggunakan teknik accidental sampling, sebanyak 30 sampel.

\section{Metode Analisis Data}

Anaisis data yang digunakan dalam penelitian ini adalah analisis deskriptif terhadap penilaian konsumen tentang variabelvariabel product (produk), price (harga), place (tempat), promotion (promosi), people (sumber daya manusia), process (proses), physical evidence (lingkungan fisik tempat). Pengukuran dilakukan dengan 5 kategori yaitu sangat tidak setuju (STS), tidak setuju (TS), netral $(\mathrm{N})$, setuju (S), sangat setuju (SS). 


\section{HASIL DAN PEMBAHASAN}

\section{Deskripsi Lokasi Penelitian}

Chatime adalah sebuah kedai minuman yang sudah menyebar luas cabangnya salah satunya terletak di kota Manado yaitu tepatnya di Manado Town Square 3, lantai 1 unit 47, jalan Pierre Tendean, Sario kota Manado. Yang memiliki luas, terbagi dengan 3 bagian ruang tempat:

1. Bagian kiri: Tempat duduk atau bersantai konsumen

2. Bagian kanan: Store Chatime atau kasir

3. Bagian belakang kasir: Terdapat dapur mini Chatime yaitu bagian produksi atau pengolahan minuman.

Sumber: Diolah dari data primer 2020.

\section{Karakteristik Responden}

Karakteristik responden menurut umur, pendidikan, dan pekerjaan dapat dilihat pada Tabel-tabel berikut.

Tabel 1. Jumlah Responden Menurut Umur

\begin{tabular}{cccc}
\hline No. & Umur & $\begin{array}{c}\text { Jumlah } \\
\text { Responden }\end{array}$ & $\begin{array}{c}\text { Persentase } \\
(\boldsymbol{\%})\end{array}$ \\
\hline 1 & $11-25$ & 18 & 60,00 \\
2 & $26-45$ & 7 & 23,33 \\
3 & $46-65$ & 5 & 16,67 \\
\hline & Jumlah & $\mathbf{3 0}$ & $\mathbf{1 0 0}$ \\
\hline
\end{tabular}

Sumber: Diolah dari data primer 2020

Tabel 2. Jumlah Responden Menurut Pendidikan

\begin{tabular}{clcc}
\hline No. & Pendidikan & $\begin{array}{c}\text { Jumlah } \\
\text { Responden }\end{array}$ & $\begin{array}{c}\text { Persentase } \\
(\mathbf{\%})\end{array}$ \\
\hline 1 & SD & 2 & 6,67 \\
2 & SMP & 5 & 16,67 \\
3 & SMA & 8 & 26,67 \\
4 & Perguruan & 15 & 50,00 \\
& Tinggi & & \\
\hline & Jumlah & $\mathbf{3 0}$ & $\mathbf{1 0 0}$ \\
\hline
\end{tabular}

Sumber: Diolah dari data primer 2020

Tabel 3. Jumlah Responden Menurut Pekerjaan

\begin{tabular}{clcc}
\hline No. & Pekerjaan & $\begin{array}{c}\text { Jumlah } \\
\text { Responden }\end{array}$ & $\begin{array}{c}\text { Persentase } \\
(\mathbf{\%})\end{array}$ \\
\hline 1 & Pelajar & 13 & 43,33 \\
2 & Karyawan & 8 & 26,67 \\
3 & Pegawai & 7 & 23,33 \\
4 & Ojek online & 2 & 6,67 \\
\hline & Jumlah & $\mathbf{3 0}$ & $\mathbf{1 0 0}$ \\
\hline
\end{tabular}

Sumber: Diolah dari data primer 2020

\section{Analisis 7P Minuman Chatime Manado Town Square}

Berdasarkan hasil data yang didapatkan terhadap 30 responden maka dapat dideskripsikan tentang product, price, place, promotion, people, process, physical evidence sebagai berikut.

\section{Product (Produk)}

Penilaian konsumen terhadap product (produk) Chatime di Manado Town Square berdasarkan kualitas, variasi, penyajian, produk tersedia, tekstur produk dan warna, kemasan, dapat dilihat pada Tabel 4 berikut.

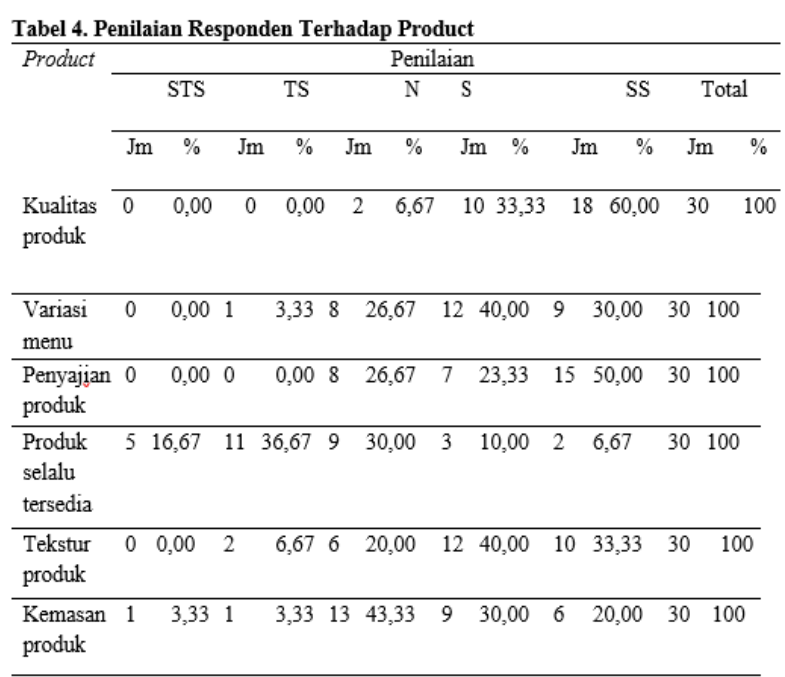

\section{Price (Harga)}

Penilaian konsumen terhadap price (harga) Chatime di Manado Town Square berdasarkan harga yang terjangkau, harga sesuai dengan kualitas produk, harga dapat berubahubah, dapat dilihat pada Tabel 5 berikut.

\begin{tabular}{|c|c|c|c|c|c|c|c|c|c|c|}
\hline \multirow[t]{3}{*}{ Price } & \multicolumn{10}{|c|}{ Penilaian } \\
\hline & \multicolumn{2}{|c|}{ STS } & \multicolumn{2}{|r|}{ TS } & \multicolumn{2}{|r|}{$\mathrm{N}$} & \multicolumn{2}{|r|}{$\mathrm{S}$} & SS & Total \\
\hline & $\mathrm{Jm}$ & $\%$ & $\mathrm{Jm}$ & $\%$ & $\mathrm{Jm}$ & $\%$ & $\mathrm{Jm}$ & $\%$ & $\mathrm{Jm} \%$ & Jm $\%$ \\
\hline $\begin{array}{l}\text { Harga } \\
\text { terjangkau }\end{array}$ & 1 & 3,33 & 2 & 6,67 & 10 & 33,33 & 8 & 26,67 & $9 \quad 30,00$ & $30 \quad 100$ \\
\hline $\begin{array}{l}\text { Harga } \\
\text { sesuai } \\
\text { kualitas } \\
\text { produk }\end{array}$ & 0 & 0,00 & 1 & 3,33 & 9 & 30,00 & 13 & 43,33 & $\begin{array}{ll}7 & 23,33\end{array}$ & $\begin{array}{ll}30 & 100\end{array}$ \\
\hline $\begin{array}{l}\text { Harga } \\
\text { dapat } \\
\text { berubah- } \\
\text { ubah }\end{array}$ & 0 & 0,00 & 0 & 0,00 & 8 & 326,6 & 76 & 20,00 & 1653,33 & $30 \quad 100$ \\
\hline
\end{tabular}




\section{Place (Tempat)}

Penilaian konsumen terhadap place (tempat) di Chatime Manado Town Square berdasarkan lokasi mudah dijangkau, lokasi strategis dapat dilihat pada Tabel 6 berikut.

Tabel 6. Penilaian Responden Terhadap Place

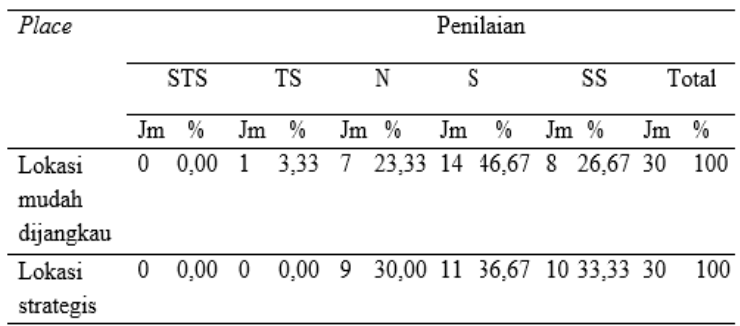

\section{Promotion (Promosi)}

Penilaian konsumen terhadap promotion (promosi) di Chatime Manado Town Square berdasarkan promosinya menarik dan promosi sudah meluas dapat dilihat pada Tabel 7 berikut.

Tabel 7. Penilaian Responden Terhadap Promotion

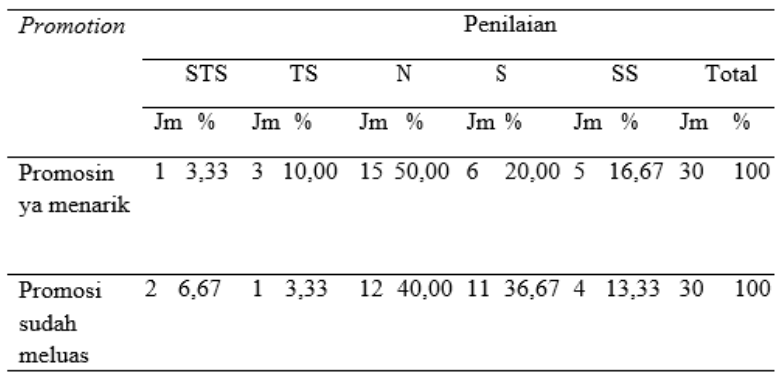

\section{People (Sumber Daya Manusia)}

Penilaian konsumen terhadap people (sumber daya manusia) di Chatime Manado Town Square berdasarkan karyawan yang baik dan ramah, karyawan yang handal dalam melayani, dan karyawan berpenampilan bersih dan rapih dapat dilihat pada Tabel 8 berikut.

Tabel 8. Penilaian Responden Terhadlap People

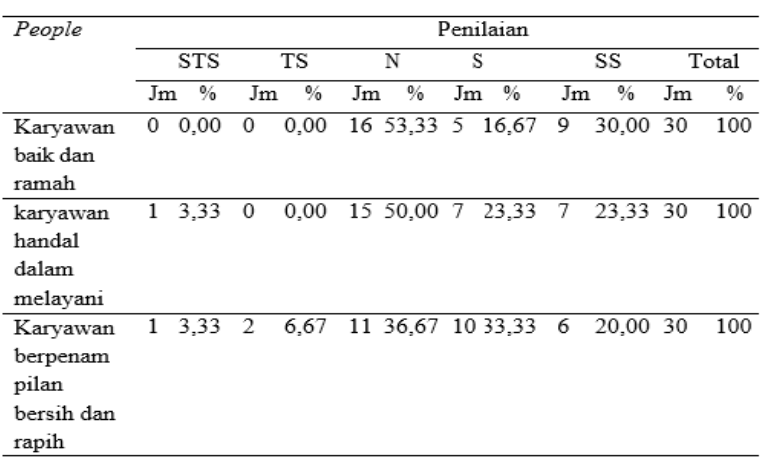

\section{Process (Proses)}

Penilaian konsumen terhadap process (proses) di Chatime Manado Town Square berdasarkan proses layanan penjualan baik, proses pengaturan jam layanan sesuai, proses untuk mendapatkan produk cepat dapat dilihat pada Tabel 9 berikut.

Tabel 9. Penilaian Responden Terhadap Process

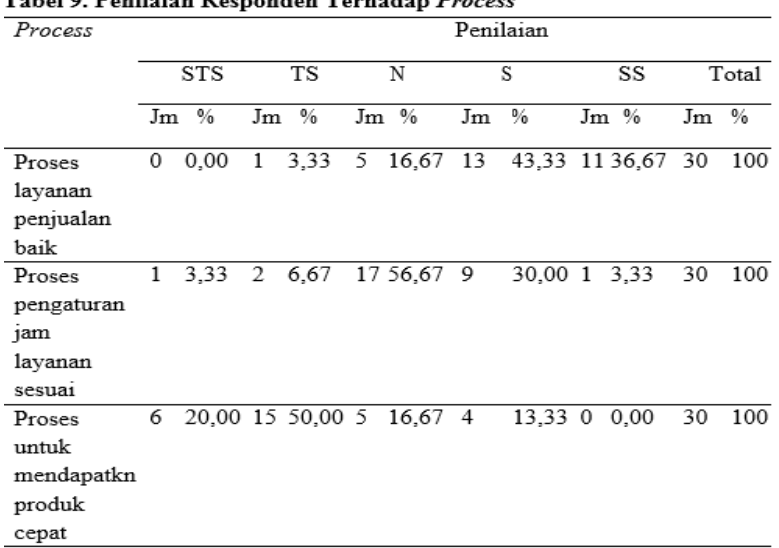

\section{Physical Evidence (Lingkungan Fisik Tempat)}

Penilaian konsumen terhadap physical evidence (lingkungan fisik tempat) berdasarkan fasilitas ruangan lengkap, design ruangan menarik, ruangan bersih dan teratur dapat dilihat pada Tabel 10 berikut.

Tabel 10. Penilaian Responden Terhadap Physical Evidence

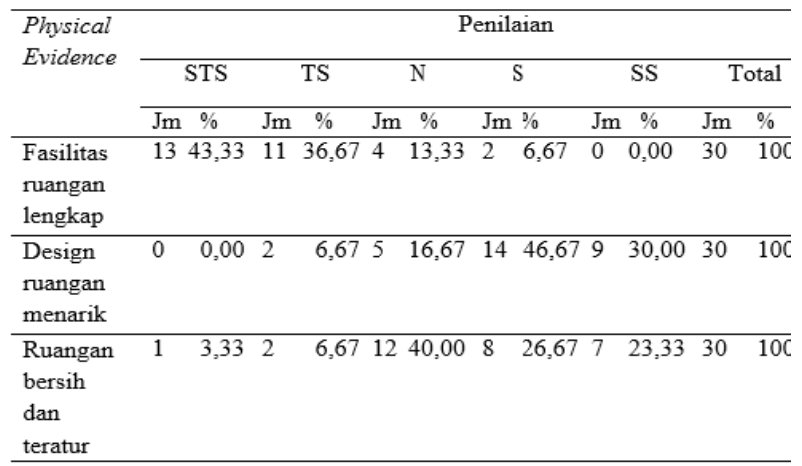

\section{KESIMPULAN DAN SARAN}

\section{Kesimpulan}

Berdasarkan hasil penilaian konsumen, dapat disimpulkan bahwa unsur komponen $7 \mathrm{P}$ product konsumen menilai setuju, hanya saja pada produk selalu tersedia konsumen menilai tidak setuju karena menurut konsumen, Chatime Manado Town Square masih sering kehabisan 
stok minuman tertentu. Pada price dan place konsumen menilai setuju. Promotion dan people konsumen menilai netral. Pada bagian process konsumen menilai setuju, hanya saja pada bagian proses untuk mendapatkan produk cepat konsumen menilai tidak setuju karena menurut konsumen, proses untuk mendapatkan produk harus menunggu antrian dan masih memerlukan waktu yang cukup lama untuk mendapatkan produk. Kemudian pada physical evidence konsumen menilai setuju tetapi pada bagian fasilitas ruangan lengkap konsumen menilai sangat tidak setuju karena menurut konsumen tidak terdapat wifi serta konsumen merasa meja dan tempat duduk yang masih kurang.

\section{Saran}

Dalam pemasaran minuman Chatime di Manado Town Square, sebaiknya perlu memperbaiki komponen 7P yang ada, seperti produk yang masih sering kehabisan stok minuman tertentu, kemudian proses untuk mendapatkan produk yang masih memerlukan waktu yang cukup lama, serta fasilitas ruangan yang dirasa masih kurang lengkap.

\section{DAFTAR PUSTAKA}

Antarnews.com, 2013. Info Franchise And Concept Business. Melalui http://www.franchiseand-conceptbusiness.com diakses Tanggal 3 Juli 2019 jam 23:10.

Indriyani, A, 2014. Pengaruh Bauran Pemasaran Terhadap Keputusan Pembeli Di Chatime Cihampelas Walk Bandung. Skripsi. Fakultas Ekonomi Dan Bisnis Universitas Telkom Bandung.

Kementrian Perindustrian, 2018. Industri Makanan Dan Minuman 2018. Melalui https://www.google.com/bisnis.tempo.co/i ndustri- makanandan-minuman-tum buh867-persen-triwulan-ii-2018 diakses Tanggal 17 Juli 2019 jam 19:26.

Kotler, P \& Keller, 2008. Manajemen Pemasaran. Edisi 13 Jilid 1 Erlangga: Jakarta.

Payne, A, 2001. Pemasaran Jasa, Penerbit Andi, Yogyakarta.

Sri Rezeki, A, 2016. Pengaruh Brand Image Terhadap Keputusan Pembelian Pada Chatime. Skripsi. Fakultas Ilmu Terapan Universitas Telkom Bandung.

Triyono, P, 2019. AsosiasiIndustri Minuman Ringan. https://www.industriminuman ringan.com/produksi-indu stri-minumanringan-pada-tahun-2019 diakses Tanggal 02 Agustus 2020. Jam 20.00. 